\title{
Psychobiological risk factors for suicidal thoughts and behaviors in adolescence: a consideration of the role of puberty
}

\author{
Tiffany C. Ho ${ }^{1,2} \cdot$ Anthony J. Gifuni ${ }^{1,3} \cdot$ Ian H. Gotlib ${ }^{1}$
}

Received: 17 April 2020 / Revised: 3 May 2021 / Accepted: 11 May 2021 / Published online: 11 June 2021

(c) The Author(s) 2021. This article is published with open access

\begin{abstract}
Suicide is the second leading cause of death among adolescents. While clinicians and researchers have begun to recognize the importance of considering multidimensional factors in understanding risk for suicidal thoughts and behaviors (STBs) during this developmental period, the role of puberty has been largely ignored. In this review, we contend that the hormonal events that occur during puberty have significant effects on the organization and development of brain systems implicated in the regulation of social stressors, including amygdala, hippocampus, striatum, medial prefrontal cortex, orbitofrontal cortex, and anterior cingulate cortex. Guided by previous experimental work in adults, we also propose that the influence of pubertal hormones and social stressors on neural systems related to risk for STBs is especially critical to consider in adolescents with a neurobiological sensitivity to hormonal changes. Furthermore, facets of the pubertal transition, such as pubertal timing, warrant deeper investigation and may help us gain a more comprehensive understanding of sex differences in the neurobiological and psychosocial mechanisms underlying adolescent STBs. Ultimately, advancing our understanding of the pubertal processes that contribute to suicide risk will improve early detection and facilitate the development of more effective, sex-specific, psychiatric interventions for adolescents.
\end{abstract}

\section{Introduction}

Suicide is the second leading cause of death among adolescents ages 10-24 years worldwide [1] and accounts for $17.7 \%$ of all deaths in youth ages $15-24$ years in the United States [2]. Although suicide has a relatively low prevalence, over the past 10 years suicide rates in the US have increased by $76 \%$ in youth ages $15-19$ years and, more alarmingly, by $300 \%$ in youth ages 10-14 years [3]. Despite the urgency of suicide as a public health problem, research examining predictors of suicidal thoughts and behaviors (STBs) has had limited clinical impact, particularly in adolescents $[4,5]$. Adolescents report a higher proportion of suicidal

Tiffany C. Ho

tiffany.ho@ucsf.edu

1 Department of Psychology, Stanford University, Stanford, CA, USA

2 Department of Psychiatry and Weill Institute for Neuroscience, University of California, San Francisco, San Francisco, CA, USA

3 Psychiatry Department and Douglas Mental Health University Institute, McGill University, Montréal, QC, Canada ideation and attempts than do adults, making this a critical developmental period during which to identify early risk factors for STBs [6]. Indeed, the fact that adolescent samples represent only $20 \%$ of the literature on predictors of STBs further underscores the need for more research with this age group [5].

While clinicians and researchers recognize that predictors of STBs are multidimensional-including genetic, epigenetic, neurobiological, psychosocial, and environmental factorsthe marked increase in the prevalence of STBs (and mental health conditions more generally) during adolescence [7] suggests that this developmental period, in which the confluence of these multidimensional influences contributes to elevated risk, is unique $[8,9]$. In this context, we contend that one critical factor is puberty. The onset of puberty initiates a neuroendocrine cascade that shapes the maturation of neural circuits that underlie a range of socioemotional and cognitive functioning, including emotion regulation and impulse control. Impaired emotion regulation and impulse control both significantly contribute to the emergence of mental disorders in the face of environmental risk factors (e.g., life stress) that influence neurodevelopmental trajectories, result in the generation and experience of additional psychosocial stress, and, thus, may represent an important pathway to developing 
STBs. Other notable aspects of development, such as pubertal timing, and factors that may drive atypical pubertal timing (e.g., exposure to early adversity), are also recognized as important in affecting the development of adolescent-onset psychiatric disorders, including STBs [10]. Indeed, atypical pubertal timing results not only in corresponding changes in neuroendocrine systems but also significant shifts in social identity and perceived status may explain sex differences in the emergence and course of STBs (and related mental health conditions that substantially increase the risk of STBs).

The goal of this review paper is to elucidate how pubertal changes contribute to STBs in adolescence. While we do not regard puberty-related processes as primary determinants of STBs, we posit that exposure to sex hormones during adolescence initiates a period of plasticity in neural circuits that are sensitive to social context (including social stressors that amplify emotion dysregulation and impulse control in ways that increase risk for STBs) and that may be target mechanisms for treatment of STBs, We further contend that these processes are especially critical to consider in adolescents who have existing vulnerabilities, including neurobiological sensitivity to hormonal changes, exposure to adverse psychosocial experiences during early development, and underlying mental disorders. In the following sections, we: (1) present an overarching framework and highlight specific brain circuits involved in social cognition, emotion regulation, and impulse control that are relevant to understanding STBs in adolescence; (2) review basic experimental findings in adults that show the effect of pubertal hormones on behaviors relevant to suicide risk and survey the conflicting correlational literature on hormones with STBs in adolescents; (3) discuss the role of pubertal timing and sex differences in these processes; and (4) advance recommendations for future research in this area.

\section{Puberty as a driver of neuroendocrine mechanisms relevant for understanding adolescent STBs}

Contemporary theories of suicide have been informed primarily by data from adults $[11,12]$, it is unclear whether these theories-or specific components of associated models-extend to adolescents. Moreover, few theories of suicidality explicitly integrate biological factors, including endocrine or neural factors (with exceptions [12-14]). Here, we posit that adolescent STBs result from a pathological response to stress during a time when the neurobiological systems that regulate stress are recalibrating. There is extensive evidence that STBs in adolescents are often preceded by life stressors, particularly stressors characterized by interpersonal rejection, loss, or conflict [15-17]. Social rejection in particular is a commonly experienced stressor during adolescence due to unstable romantic and peer relationships, and is a potent trigger for negative emotions $[18,19]$. In this context, emotion-related impulsivity-the tendency to react impulsively during experiences of heighted affective states [20]—-may contribute to adolescent risk for STBs. Indeed, both peer-related stressors [21, 22] and emotion-related impulsivity [23] have been shown separately to predict STBs in adolescents.

We argue here that hormonal changes during puberty alter the development of brain circuits implicated in the regulation of social stressors. The brain is a target organ for all of the pubertal hormones we review, and receptors for these hormones are expressed abundantly in several key structures that comprise brain networks governing social cognition, emotion regulation, and impulse control generally (and social rejection and emotion-related impulsivity specifically) [24, 25], including the amygdala, hippocampus, striatum, anterior cingulate cortex (ACC), medial prefrontal cortex (mPFC), and orbitofrontal cortex (OFC). The amygdala, hippocampus, and ACC comprise a network of regions implicated in detecting social salience; the amygdala and mPFC comprise a key emotion regulatory circuit; the striatum and frontal regions including OFC comprise circuits underlying reward valuation and impulse control. It is important to note that many of these regions already exhibit sexual dimorphism during adolescence, including larger amygdala and hippocampal volumes in boys, greater variance in the hippocampus and striatum in boys than in girls, sex differences in white matter organization of callosal, cerebellar, and long-range association tracts (for a review, see [26]), and sex differences in the developmental trajectories of frontoparietal networks [27]. Moreover, several of these regions have been highlighted in a recent review of neuroimaging markers associated with STBs across the lifespan [28]; however, those authors did not consider the importance of pubertal development in explaining the neuroendocrine basis of the emergence of STBs. We contend that this is a critical factor to consider, given emerging evidence that sex differences in these brain circuits during adolescence appear to be explained, at least in part, by changes in pubertal hormones $[29,30]$. Thus, we contend that the social landscape, and most notably environmental stressors, experienced by boys and girls begins to differ during puberty, and that these differences, in conjunction with sex-specific hormonal effects on brain maturation, may explain important sex differences in STBs that emerge by mid-adolescence.

\section{Pubertal hormones and suicide-relevant thoughts and behaviors}

Puberty is composed of two phases: adrenarche and gonadarche. During adrenarche, which typically begins around ages 7-8 years, the adrenal glands produce increasing levels 
of the hormones dehydroepiandrosterone (DHEA) and testosterone $[31,32]$. Gonadarche is a longer process that typically takes $4-5$ years, beginning around ages $9-10$ and occurring on average a year earlier in girls than in boys [33]. Gonadarche is triggered by the activation of hypothalamicpituitary-gonadal (HPG) axis, which leads to rising levels of luteinizing hormone (LH) and follicle-stimulating hormone (FSH). The release of LH and FSH initiates the development of the gonads, which, in turn, leads to increases in sex hormones-specifically, testosterone in boys and estradiol (the predominant estrogen during adolescence) and progesterone in girls-and, by early to mid-adolescence, the development of secondary sex characteristics and other physical changes [32]. Importantly, these hormones cross the blood brain barrier, influence brain development, and affect a wide variety of signaling pathways (e.g., neurotransmitter activity) that underlie mood and cognition [25]. Thus, puberty involves transformation across virtually every psychobiological domain-endocrine, neural, physical, cognitive, and socioemotional—and represents a vulnerable time during which STBs may emerge.

Prevalence rates of STBs begin to increase after age 12 but peak in later adolescence, suggesting that it is not simply the rise in these hormones that accounts for the increase in STBs, given that these endocrine changes begin much earlier than age 12. Instead, the organizational effects of pubertal hormones play a major role in risk for STBs in adolescence. Organizational effects are those that occur during sensitive periods of development that lay the foundation for sex-typical brain and behavioral phenotypes and, thus, have an impact even in the absence of circulating levels of the hormones. In contrast, activational effects facilitate the expression of behaviors under specific contexts but are temporary and occur only when the hormones in question are present [34]. Evidence for organizational effects of hormones during adolescence comes from studies demonstrating that the same developmental processes (e.g., neurogenesis, synaptic pruning, dendritic branching, apoptosis) that occur during the perinatal period as a result of surging levels of gonadal hormones also occur during puberty $[35,36]$. These studies suggest that puberty opens a sensitive window for experiencedependent plasticity in neural circuits that underlie higherorder processing of social stimuli, thereby rendering adolescence- a time of increased exposure to social stressors-a vulnerable period for the onset of stress-related mental health problems (Fig. 1). At the same time, it is possible that ongoing fluctuations in hormone levels are also related to STB risk through their activational effects on neurotransmitter systems, particularly in the context of responding to social stressors, and that these effects are more relevant for adolescents with a neurobiological sensitivity to hormonal changes.

Below, we review studies investigating ovarian (estradiol and progesterone), testicular (testosterone), and adrenal
(DHEA) hormones in relation to STBs and, importantly, their impact on the structural development and function of specific brain circuits implicated in social cognition, emotion regulation, and impulse control. A summary of this section is outlined in Table 1 and Fig. 1B. Before reviewing the correlational literature in adolescents, within each respective section, we first review basic experimental studies that provide insight concerning the effects of estradiol, progesterone, testosterone, and DHEA on human behaviors relevant to suicide risk in adults in order to provide a more reliable context for the actions of these hormones.

Finally, because ovarian hormones have been investigated almost exclusively in females in this context and, similarly, androgen hormones overwhelmingly in males, our review of the association of these hormones with brain and behavioral outcomes inherently raises issues of sex differences or sex-specific effects in these processes; we discuss these issues in more detail in a later section (D. Consideration of sex differences).

\section{Ovarian hormones (estradiol and progesterone)}

Estradiol, progesterone, and their neurosteroid metabolites all increase and begin to fluctuate cyclically in girls during puberty [34]. Consequently, the vast majority of research in this area has focused on females (for reviews, see [14, 37]). To provide a context for understanding the effects of estradiol and progesterone administration on behaviors relevant to suicide risk, we will first briefly review studies that controlled hormone conditions in women with affective symptoms and premenstrual dysphoric disorder (PMDD), for whom suicide risk is elevated compared to the general population [38, 39].

Decades of research have shown that there are no differences between women with and without PMDD in ovarian hormone levels or related neurosteroids (e.g., allopregnanolone) but that suppressing ovarian hormones reduces or eliminates symptoms of PMDD (for a review, see [40]). A recent study that controlled for ovarian hormone secretion and exposure in women with PMDD has helped to clarify these two seemingly opposing findings [41]. In that study, women with PMDD who responded to a gonadotropin-releasing hormone agonist treatment were given placebo for one month before being administered continuous estradiol/progesterone for three months; researchers found that changes from low to high levels of ovarian hormones, but not absolute levels of ovarian hormones, were associated with increases in negative affect [41]. Together, these data suggest that neurobiological sensitivity to hormone changes is an important factor that may explain certain clinical phenomena, such as PMDD and suicide risk. Indeed, a recent review has covered this topic extensively in adult women, demonstrating that cyclical 
A
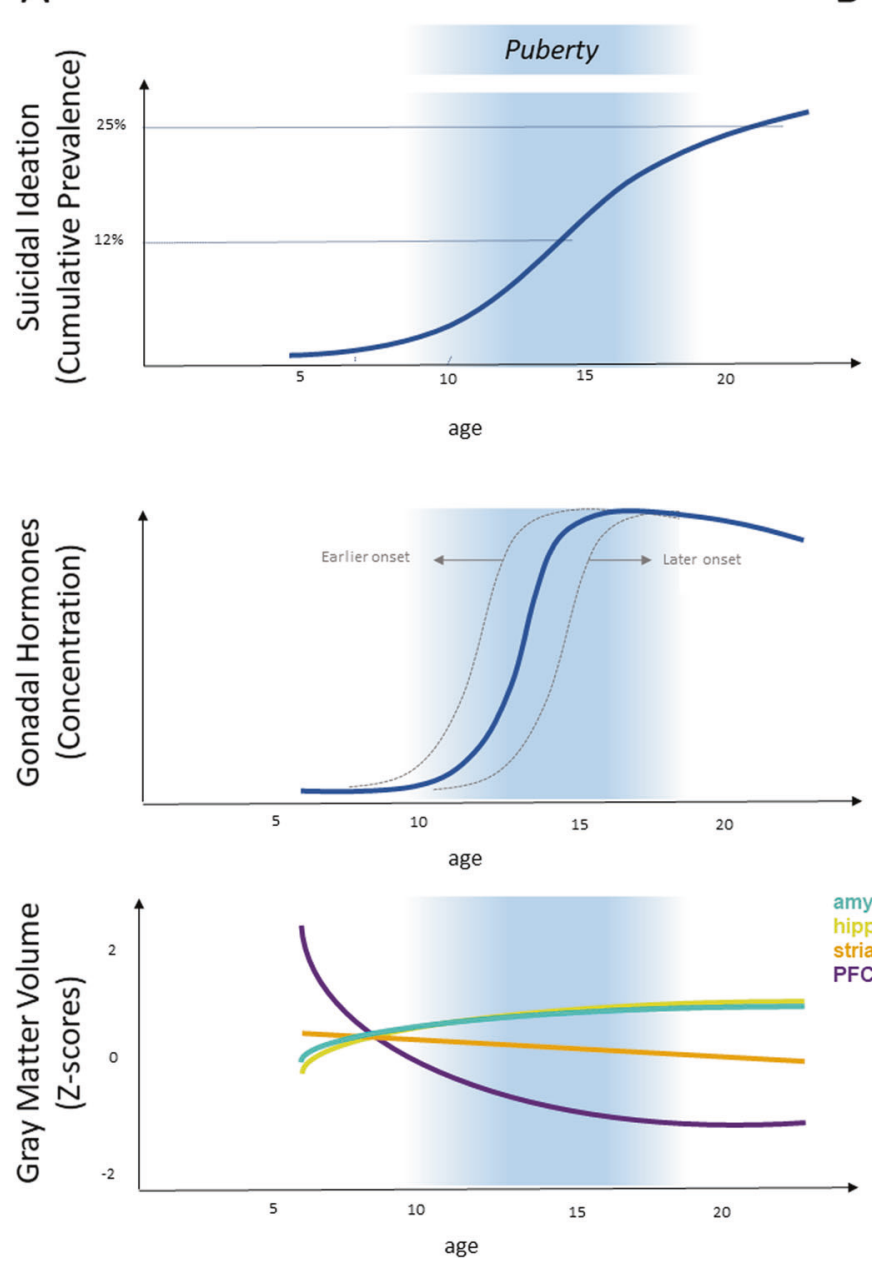

Fig. 1 Summary of prevalence rates of suicidal ideation, concentration of sex steroids, and brain volume as a function of age and typical associations between pubertal hormones and brain structures reported the extant literature. A) Graphical depictions of prevalence rates of suicidal ideation, concentrations of sex steroids, and brain volume as a function of age. Shaded region indicates

hormone changes may play an important role in "acute risk for daily suicidal ideation, planning, and intent" in individuals with sensitivity to hormone changes [14]. We have extended this theoretical model to adolescents, proposing that in those who possess a neurobiological sensitivity to hormonal changes, the normative fluctuations during this transitional period, coupled with adolescent-typical experiences of greater exposure to life stressors, may exacerbate the effects of these processes on emotion regulatory and impulse control circuits. Indeed, results from studies that have investigated suicide risk in adult women across the menstrual cycle have been inconsistent. These studies have typically assessed levels of estradiol and progesterone during different phases of the menstrual cycle [42-44], and in women with low levels of estradiol and progesterone (e.g., amenorrhea or menopause [45]). While some

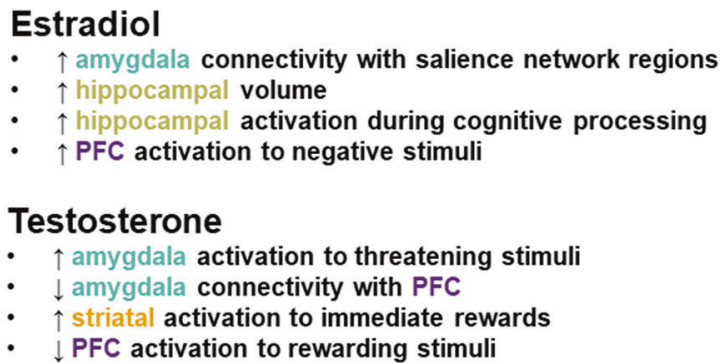

\section{Progesterone}

- $\quad \uparrow$ hippocampal connectivity with PFC

- $\quad \uparrow$ striatum activation during cognitive processing

- $\quad \uparrow P F C$ activation during cognitive processing

\section{DHEA}

- $\quad \downarrow$ ACC activation to social stimuli

- $\uparrow A C C$ connectivity with amygdala to social stimuli

- $\uparrow$ hippocampal volume
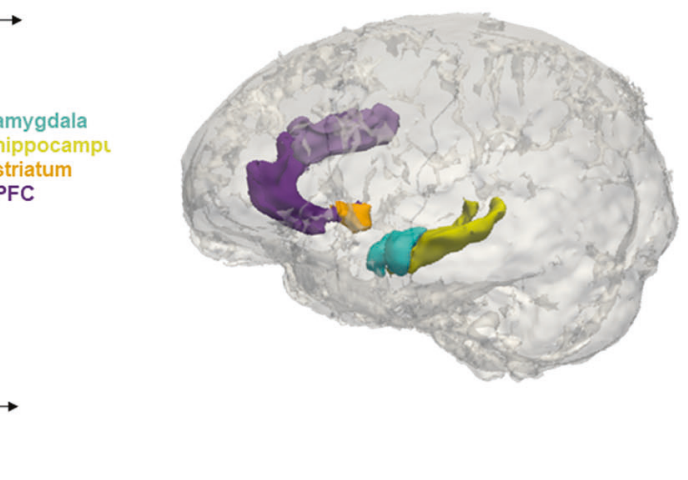

puberty. The schematized trajectories of gray matter volume adjusted for total brain volume are based on data reported in [162]. B) Summary of typical associations between pubertal hormones and brain structures from both adolescent and adult samples. ACC anterior cingulate cortex, AMYG amygdala, HPC hippocampus, MPFC medial prefrontal cortex, OFC orbitofrontal cortex, STM striatum.

investigators have reported that a higher risk of suicide attempts and more severe suicidal thoughts and intentions are associated with relatively low or declining levels of estradiol and progesterone (i.e., during the early follicular/ menstrual or pre-menstrual phases), other researchers have not found differences in estradiol or progesterone between depressed women with and without STBs [46] or effects of the menstrual cycle on suicide attempts in women with PMDD [39].

The fact that there has been no evidence of differences in ovarian hormone levels or in cyclical changes in female adolescents with and without STBs is consistent with the previously aforementioned studies in adult women with reproductive mood disorders where the effect of menstrual cycle and/or ovarian hormone levels on STBs in adult women is absent. One interpretation is that it is the 


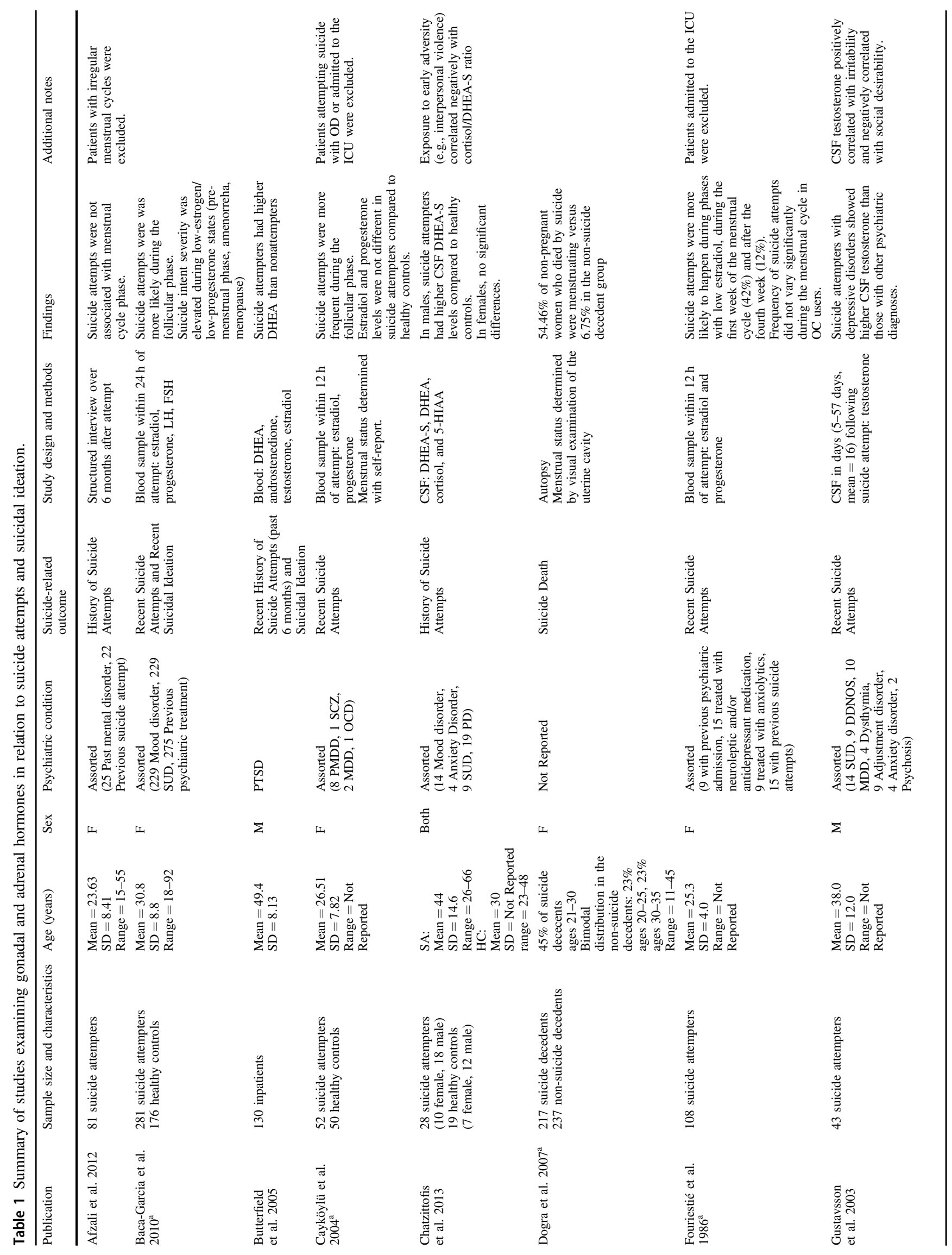




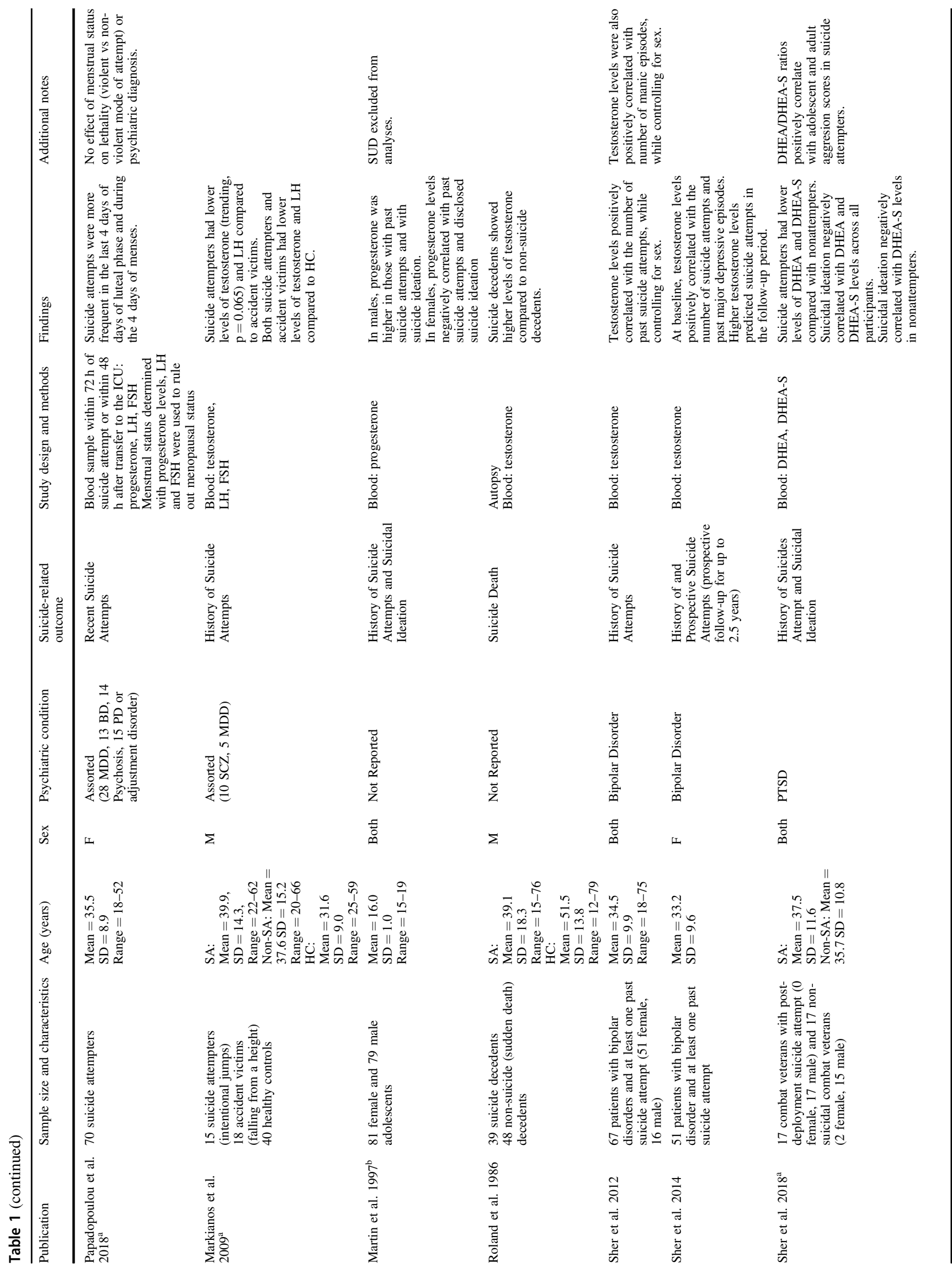




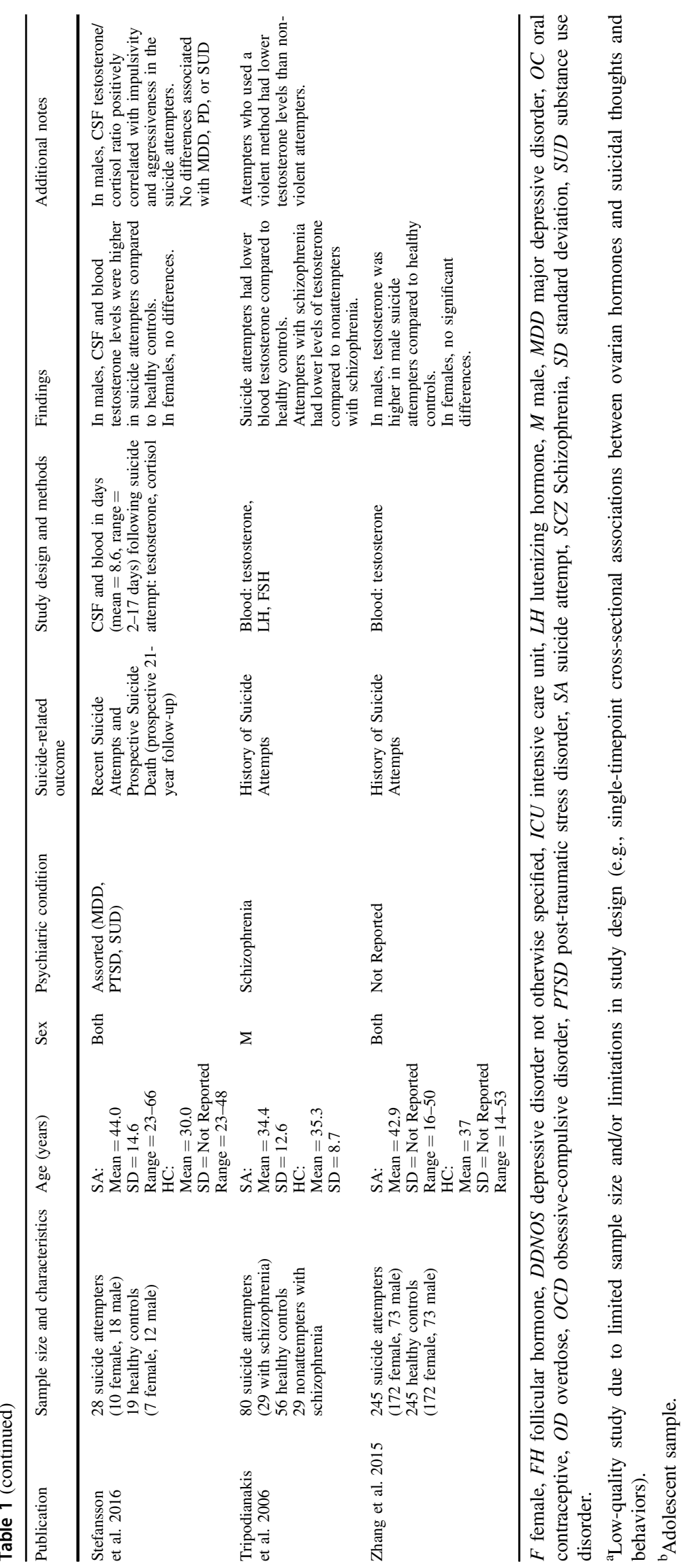


neurobiological sensitivity to changes in estradiol and progesterone-rather than between-person differences in levels of these hormones-that represents a key trait-like source of variance for understanding suicide risk in the context of puberty, a time when the stability of these hormone dynamics is still in flux [47]. Intensive (e.g., daily samples) longitudinal studies conducted in adult women have also provided little evidence that hormone levels at a single point in time are correlated with levels within the same cycle and also for subsequent cycles, particularly for estradiol [48, 49]. It is also important to note that both between-person and within-person variability of ovarian hormone levels are affected by multiple confounds that investigators ought to consider, including, but not limited, to cycle length [50], diurnal effects [51], cycle phase [48, 49], effects of study participation [48], anovulation [52], culture and/or diet [53], and personal and family medical history (e.g., polycystic ovary syndrome, breast cancer $[48,54])$. Nevertheless, dense-sampling studies have demonstrated robust between-person effects of menstrual phase, such that progesterone is reliably higher in the luteal phase relative to the follicular phase and, albeit to a lesser extent, estradiol is higher in the follicular phase relative to the luteal phase [48, 49]. We note in Table 1 which studies employ non-experimental cross-sectional designs and that attempt to relate ovarian hormones without consideration of these relevant factors (e.g., cycle phase).

Given these limitations in measuring ovarian hormones, it is not surprising that little is known about the effects of estradiol and progesterone on the human brain in general, much less on the circuits we have hypothesized are implicated in STB risk. Nonetheless, there is evidence that estrogen receptors are expressed strongly in brain regions involved in social cognition broadly and social rejection specifically, including the amygdala, hippocampus, ACC, and vmPFC [55-58]. Several studies have also found that women with comparably higher levels of estradiol (endogenous or synthetic) show greater amygdala-based restingstate functional connectivity and activation in ACC and vmPFC, which are key regions involved in processing salient information [59-61]. Similarly, longitudinal studies with naturally cycling women have documented larger hippocampal gray matter volumes during periods of relatively high estradiol (late follicular/preovulatory phases) than of relatively low estradiol early follicular/premenstrual phases [62, 63].

There is also evidence from functional magnetic resonance imaging (fMRI) studies wherein groups of women during different phases of their menstrual cycle are compared that show that relatively higher levels of estradiol (pre-ovulatory phase) are associated with greater activation of the hippocampus during both cognitive tasks [64] and affective stress tests [65], and with stronger functional connectivity of the hippocampus with brain regions involved in processing salient information [63]. Similarly, higher levels of progesterone (luteal phase) have also been found to be associated with activation of the striatum and PFC during cognitive processing [64]. Finally, results from fMRI studies utilizing dense-sampling designs of naturally cycling women have reported intriguing, albeit inconsistent, results. One study found no effects of estradiol across the menstrual cycle on intrinsic connectivity patterns [66], whereas another found that higher levels of estradiol drove stronger subsequent connectivity within attention networks (specifically among brain circuits that are implicated in internally focused attentional states and externally focused attentional states) [67]. In contrast, one study found that progesterone mediated patterns of positive functional connectivity between the hippocampus and PFC [66] whereas another study found that higher levels of progesterone was associated with lower connectivity across all networks [67]. It is clear that additional research is needed to clarify the magnitude and directionality of the effects of estradiol and progesterone on patterns of brain connectivity, particularly in adolescents, and their effects on longer-term neurodevelopmental trajectories. It is also critical that researchers work to characterize the extent to which these hormones effect brain circuits specific to STBs, or alternatively, whether they are implicated in mental illness risk more broadly. Nevertheless, the studies we have reviewed provide initial evidence that brain circuits that support the regulation of affectively salient stimuli are sensitive to the effects of estradiol and progesterone; importantly, these same circuits have also been shown to be affected in adults and adolescents with STBs [28, 68].

Additional research is also needed to elucidate the precise neural mechanisms by which estradiol may impact the development of brain circuits, including its effects on neurotransmitters. Estradiol has also been found to alter serotonin transmission, binding, and metabolism by increasing the production of tryptophan and inhibiting the expression of the serotonin reuptake transporter gene (for a review, see [69]). Serotoninergic abnormalities in the number of serotonergic neurons and in serotonin transportation, receptor binding, and levels have all been found in victims of suicide [70, 71] (for a review, see [72]). Serotonin has been shown to be associated with cortisol reactivity to stressors [73] and positively associated with greater $5-\mathrm{HT}_{1 \mathrm{~A}}$ receptor binding-which could contribute to lower serotonin signaling by inhibiting further serotonin release into the synapse-in depressed patients who died by suicide versus both depressed and psychiatrically healthy individuals who did not die by suicide [74]. Similarly, allopregnanolone, a progesterone metabolite, binds to $\mathrm{GABA}_{\mathrm{A}}$ receptors, which mediates the majority of inhibitory signaling in the brain [75] and plays an important role in downregulating the 
HPA-axis in response to acute stressors [76]. Several studies have found that stress exposure alters the availability of $\mathrm{GABA}_{\mathrm{A}}$ receptors as well as their composition and sensitivity to neurosteroid regulation, which, in turn, can influence subsequent responses to stress [77-79]. Emerging data has also implicated GABA dysfunction in STBs, whereby depressed patients who died by suicide showed a higher expression of genes that encode for proteins involved in GABAergic synaptic transmission in the ACC and a lower expression of these genes in the dorsolateral PFC than did both depressed and psychiatrically healthy individuals who did not die by suicide [80]. Future work is needed to explicitly investigate the extent to which patterns of structural or functional connectivity of circuits involving the amygdala, hippocampus, ACC, and PFC that are developing in response to puberty-related changes in estradiol and progesterone (and related neurosteroids) exhibit corresponding changes in neurotransmitter systems that support socioemotional processes relevant to STB risk.

\section{Testosterone}

Unlike ovarian hormones, which have been studied primarily in female adolescents, investigators have found in both sexes that levels of androgens are associated with appetitive behaviors, aggression, competition, and other related social behaviors that are relevant to STB risk [81, 82]. In female adolescents, the sex steroid with the most androgenic activity is DHEA, which is produced by the adrenal cortex (discussed separately in the following section); in males adolescents, it is testosterone [31, 32].

In contrast to the data published thus far on ovarian hormones, there is evidence of strong within-person reliability and stability in testosterone levels in both men and women. Indeed, some researchers contend that levels of testosterone are trait-like [83]. Perhaps not surprising, testosterone has been linked more strongly with STB risk, and specifically with suicide attempts, than has any other pubertal hormone (see Table 1). However, the empirical findings thus far have been mixed (for opposing reviews, see $[84,85])$. Several researchers have theorized that testosterone is linked to suicidal behaviors through its modulation of emotion-related impulsivity and impulsive aggression, which are considered to be among the most robust predisposing traits to suicidal behaviors in youth [86]. In drawing from the literature of studies in which testosterone is administered and behaviors are subsequently assessed, as well as studies that link changes in social interactions with changes in endogenous testosterone, there appear to be reliable effects of testosterone on socially motivated behaviors, including exerting dominance and displays of aggression (either physically or non-physically) and other social status seeking behaviors (for a review, see [87]).
While testosterone exert complex effects on interpersonal behavior, longitudinal studies show that the puberty-related increases in testosterone are not accompanied by a concurrent rise in aggressive behaviors [83, 88, 89]. Additional studies in animals as well as in humans [90] suggest that testosterone levels correlate more closely with social dominance, rather than aggressive behaviors. Hence, testosterone may be an important moderator of the behavioral response to events associated with loss of social status [91], which are known precipitants of STBs. In the context of adolescent STB risk, it may very well be that testosterone is a driver of heightened sensitivity to social context, which can lead to significant emotion dysregulation and impulse control and, in turn, elevated STB risk.

Consistent with these points is evidence that elevated testosterone has also been found in male adults to be associated with psychological states and individual traits associated with suicide risk, including depression severity, irritability, and impulsive aggression [92, 93]. Researchers have found higher levels of testosterone in both male and female suicide attempters than in their same-sex nonattempting counterparts [94], and in post-mortem samples of suicide completers compared to individuals who died from other causes [95]. In a recent study, male, but not female, young adults who attempted suicide had higher levels of testosterone than did age- and sex-matched healthy volunteers [92]. Thus, there studies do not preclude the possibility that testosterone levels are higher in individuals with a mental disorder than they are in healthy persons. One study found in women with bipolar disorder with a history of suicide attempt that higher testosterone levels predicted subsequent suicide attempts [96]. Interestingly, in another sample of men and women with bipolar disorder, higher levels of testosterone were associated with number of suicide attempts only after controlling for sex [97]. In contrast, other studies have found lower levels of testosterone both in male suicide attempters relative to psychiatric healthy controls [98] and in patients who were hospitalized due to accidents [99]. One possible discrepancy for these findings involves the measurement of testosterone in plasma versus cerebrospinal fluid; studies assaying plasma testosterone have typically reported inverse associations with suicide attempts. Nevertheless, it is clear that adequate clinical controls (attempters or completers relative to nonattempters who otherwise have similar clinical histories) must be included in research in order to clarify the results of these studies.

As is the case with research on ovarian hormones and STBs, no studies have examined the psychobiological mechanisms and specific brain circuits through which testosterone may drive risk for STBs in either adolescents or adults. Testosterone influences many of the same neurotransmitters as does estradiol [25]; moreover, testosterone 
can be converted into estradiol via aromization [100], adding additional complexity in these processes should be addressed in future work. That said, one pathway through which testosterone may affect mood and cognition is through altering dopaminergic neurotransmission: several studies have found evidence of differences between suicide attempters and completers in dopamine receptor density, transporter binding capacity, and metabolism [101-103], primarily in the striatum. In fact, testosterone receptors are widely expressed in dopaminergic neurons of the striatum and portions of the PFC, including vmPFC and OFC [104]. Research with both macaques and humans has documented changes in the mechanisms that underlie dopamine signaling during adolescence, which may be explained, in part, by effects of testosterone (and estrogen; for reviews, see $[105,106])$. In particular, testosterone has been shown to increase basal dopamine levels and decrease the number of enzymes that break down dopamine in the striatum and PFC [105]. Consequently, it is possible that adolescent-typical increases in testosterone during puberty, especially in boys, contribute to elevated STB risk through enhanced dopaminergic transmission. This is consistent with previous reports that, compared to depressed patients who did not die by suicide, depressed patients who die by suicide have lower growth hormone responses to apomorphine [102, 107], which is an indication of higher dopamine transporter binding [108]. Nonetheless, it is important to note that some studies provide evidence of lower dopamine (measured by lower levels of homovanillic acid and total dopamine in urine) in patients who attempted suicide versus those who did not, see [103], or of no significant associations between dopamine levels/receptor binding and STBs [109].

With respect to brain development, higher levels of pubertal testosterone have been associated with white matter organization in tracts implicated in social cognition and emotion regulation, including the uncinate fasciculus (which connects the amygdala and vmPFC) and corpus callosum in both boys [110, 111] and girls [29, 112]. Several researchers have documented other effects of testosterone on adolescent and young adult brain and behavior. Human neuroimaging studies using fMRI have shown that in healthy young men, activation in the amygdala-a brain structure that is rich in androgen receptors [63] and is affected by circulating androgens [64] — to fearful and angry faces co-varies positively with individual differences in serum testosterone concentrations [65, 66] (but see [67] for opposing results). In an experimental study, administration of testosterone was associated with increased amygdala reactivity to threat-related stimuli in young women [113]. These results are consistent with a longitudinal study in adolescents that found that increased levels of pubertal testosterone disrupted typical coupling between the amygdala and OFC, leading to increased amygdala reactivity to threat-related stimuli in both sexes [114]. Finally, whereas in boys higher testosterone levels are associated with lower activation in the striatum and PFC during processing of emotional conflict, in girls higher testosterone levels are associated with lower activation in the $\mathrm{PCC} /$ precuneus [115]. Other investigators have shown in both boys and girls that higher levels of testosterone are associated with higher striatal activation during reward consumption [116], and with higher striatal activation when adolescents select smaller yet more immediate rewards [117]. In an observational longitudinal neuroimaging study in male and female adolescents between the ages of 8-27 years, activation in the striatum (nucleus accumbens) to rewarding stimuli peaked during adolescence, and was associated with accompanying changes in testosterone levels [118]. In a recent study, in which salivary testosterone was measured in adolescents before and after a neuroimaging scan, acute increases in testosterone were associated with smaller differences in activation between reward cues signaling reward or non-reward outcomes for a given trial in vmPFC and posterior cingulate cortex (PCC) in both sexes [119]. Thus, by altering neural processing of both negative (e.g., threatening) and positive (e.g., rewarding) valenced stimuli, testosterone may be facilitating the expression of adolescent sensation-seeking and risk-taking behavior [118] through dopaminergic transmission among these subcortical and prefrontal circuits. Certainly, these processes may not be specific to STBs and may represent a more general diathesis for mental disorders that are characterized by sensationseeking and risky behaviors; however, future research is needed to test this possibility more explicitly.

In sum, studies to date have demonstrated that higher levels of testosterone are associated with aspects of emotionrelated impulsivity in males with a history of suicidal behaviors (e.g., attempts). Higher levels of testosterone are also associated with steeper temporal discounting of rewards driven by patterns of activation in striatal, vmPFC, and OFC in both sexes; sex differences in the effect of testosterone on adolescent brain circuits appear to be most prominent in emotion-related contexts. Indeed, in adults, both endogenenous levels [120] and exogenous administration [121] of testosterone enhance risk taking. The predisposition to take risky decision has been shown to be a critical risk factor for suicidal behavior in adults [122] and, to a lesser extent given the sparse literature on this topic, in adolescents [123]. Hence, functional alterations in decision-making systems induced by puberty-related rises in testosterone levels, or their context-dependent fluctuations, might be related to suicidal risk through an increase probability of perpetrating highly risky and self-destructive behaviors in the face of overwhelming stress (particularly social stressors involving loss of desired status). Future work is needed to test explicitly whether higher levels of testosterone exacerbate affect 
striatal and PFC systems underlying maladaptive responses to social stressors that, in turn, lead to heightened risk for STBs.

\section{DHEA}

DHEA (and its sulfate, DHEA-S) is the most abundant steroid hormone in humans and is a precursor to sex steroids. Researchers have not yet examined the relation between DHEA (or DHEA-S) and STBs in adolescents; moreover, and the few studies that have been conducted with adults differ in their measurement of DHEA. One study showed that male suicide attempters had higher levels of DHEA-S than did healthy controls, and that exposure to extreme social threat (i.e., interpersonal violence) as a child was negatively correlated with the ratio of cortisol/DHEA-S [124]. Among adults diagnosed with PTSD, those who had attempted suicide had significantly higher levels of DHEA than did those without a history of attempt [125]. Another study found that, in combat veterans, the ratio of DHEA/ DHEA-S was positively correlated with total adolescent aggression scores, total adulthood aggression scores, and lifetime aggression scores in those who had attempted suicide but not in nonattempters [126].

Overall, these studies suggest that higher levels of DHEA or DHEA-S may be associated with risk for STBs. Indeed, DHEA modulates neurotransmitter systems implicated in suicidal thoughts and mood disturbances, including acting as an antagonist for GABA receptors, with genes widely expressed in hippocampus, amygdala, and striatum [127]. There is also intriguing evidence that psychiatric conditions characterized by excessive stress and elevated suicide risk lead to a downregulation of neurosteroid biosynthesisincluding the conversion of DHEA to GABAergic metabolites, such as allopregnanolone [128] — and changes in $\mathrm{GABA}_{\mathrm{A}}$ receptor subunit composition [129]. Thus, STB risk may be associated with higher levels of DHEA due to an insufficient ability to metabolize DHEA. With respect to the effects of DHEA on the adolescent brain, however, there have been a small number of studies. Thus, far investigators have found that higher levels of DHEA are associated with larger hippocampal volumes in both male and female adolescents [130] and with lower white matter organization across a broad set of white matter tracts [110]. Other studies have found that higher DHEA levels are associated with reduced cingulate activation and greater functional connectivity between the amygdala with ACC and other regions involved in processing salient information in adolescents during the processing of social stimuli (e.g., viewing fearful faces) [131]. Moreover, higher DHEA levels are associated in girls with lower activation in cingulate regions implicated in processing salience information and with greater externalizing problems [132], but in boys with stronger functional connectivity between the amygdala and inferior frontal gyrus (the opposite pattern was found in girls) and with higher anxiety symptoms [131].

Despite the heterogeneity in clinical, developmental, and demographic features across the studies reviewed in this section, there appear to be consistent associations between higher levels of DHEA and both STBs and altered structure and function of brain circuits underlying emotion regulation. In adults with clinical disorders, higher levels of DHEA (either alone or relative to cortisol) appear to be associated with STBs. In psychiatrically healthy adolescents, higher levels of DHEA are associated with reduced downregulation of affective signals in the amygdala from emotion regulatory cortical regions, including the ACC and portions of the PFC. Thus, higher levels of DHEA may disrupt the development of emotion regulatory brain circuits across adolescence in ways that increase risk for STBs when individuals are exposed to interpersonal stressors (particularly those characterized by threat). However, it is worth noting one study of psychiatrically healthy adults in which administration of exogenous DHEA reduced activation in the amygdala and hippocampus, increased activation in the vmPFC, and led to stronger connectivity between the amygdala and hippocampus during an emotion reappraisal task; moreover, decreased activation in the hippocampus during the task was associated with lower negative affect, suggesting that higher levels of DHEA improve negative mood by downregulating affective signals in the hippocampus [133]. Additional research is needed to examine whether these associations hold in clinical samples of adolescents and whether (or how) they are related to risk for STBs.

\section{Consideration of sex differences}

Across most countries, being female increases the risk of suicidal thoughts and related behaviors [5]. Despite this higher prevalence of STBs in women, men are more likely to die by suicide [134], leading to "the gender paradox of suicide." It is notable that the sex difference in suicide deaths increases dramatically in adolescence [135], suggesting that puberty plays an important role in explaining this difference (although this sex difference is now narrowing among adolescents [136], indicating that other factors, including environmental or cultural influences, are also likely). Whereas pastyear ideation, plans, and attempts tend to peak during midadolescence ( $\sim 16$ years) in girls, these rates increase steadily throughout mid- to late adolescence in boys [137, 138].

As in adults [5, 139], there are sex differences in suiciderelated outcomes in adolescents that are mediated in part by differences in lethality and mental illness. In a psychological autopsy study, adolescent male suicide victims were 
more likely to use lethal methods and had a higher prevalence of conduct disorder than did female victims [140]. A recent meta-analysis of sex-specific suicide risk in adolescents (ages 12-26 years) found distinct clinical and environmental risk factors for suicide attempt in male and female adolescents [139]. Thus, in addition to the hormonal differences that underlie sex-specific neurodevelopmental changes, different clinical conditions (externalizing disorders in boys versus mood disorders in girls) and social stressors (peer influence in boys versus direct trauma/victimization from romantic relationships in girls) may further explain or moderate these pathways to risk for STBs. Because of the sparse literature, however, it is not clear whether sex-specific risk factors are present before puberty, whether puberty affects neuroendocrine systems in sexspecific ways to increase risk for STBs, or whether boys and girls are exposed to differential environmental risk factors as a result of going through puberty. Future research should attempt to clarify the extent to which pubertal processes play a central role in STBs or whether they are implicated in mental illness more generally.

While adrenal and gonadal hormones and physical maturation are important indicators of pubertal development, other aspects of puberty may be relevant in the context of adolescent risk for STBs. Pubertal timing-the age at which individuals mature relative to their peers [141] — has been linked to individual differences in mental disorders in adolescence [142, 143]. Moreover, the timing of pubertal onset may have a different impact on developing neuroendocrine function depending on whether it occurs earlier or later in a given individual [34, 139]. Given that girls typically enter puberty earlier than do boys, considering the role of pubertal timing may also elucidate sex differences in risk for STB-as well as mental illness more generally-and accompanying endocrine and neural processes. A growing number of studies are reporting that early menarche is associated with elevated risk for suicidal ideation in adolescent girls [144-146]. In a recent longitudinal study of a large birth cohort, earlier age of menarche was associated with increased suicidal behaviors at 16 and 21 years of age [147], suggesting that earlier puberty has an enduring effect on STB risk throughout adolescence and young adulthood. In addition, considerable evidence suggests that pubertal timing is influenced by early life adversity [148], which itself is a robust predictor of STBs [149]. Thus, early puberty resulting from early adversity may be a mechanism by which suicide risk is instantiated or exacerbated in vulnerable adolescents. Finally, it is important to acknowledge that sexual orientation and identification as a sexual minority are increasingly being recognized as risk factors for STBs [150]; more research in this area is critically needed.

\section{Future directions}

No research has yet examined whether and how pubertal hormones affect neurodevelopmental trajectories of brain circuits that mediate social cognition and emotion-related impulsivity explain risk for STBs during adolescence. Studies are needed to clarify the role of pubertal timing and the multidimensional mechanisms-biological, social, cultural-by which puberty-related processes influence risk for STBs. An important next step for the field is to first establish reliable associations between pubertal hormones and adolescent brain structure and function and to then map those associations onto neural circuits underlying STBs in adolescents. Other critical knowledge gaps include disentangling neuroendocrine mechanisms that are more closely linked to suicidal thoughts versus attempts (and other selfharming behaviors) and that facilitate the transition from ideation to action [151].

Although we focused here on the effects of pubertal hormones, we should acknowledge that there is considerable evidence that HPA-axis dysfunction is associated with STBs and self-harming behaviors in adolescents $[13,21,152,153]$. Puberty is also the time when HPG-axis regulation of the HPA axis develops [154-157]. Given that the expected suppression of the HPA axis by the HPG axis [158] is disrupted in individuals at risk for STBs (due to such factors altering developmental changes in stress response and regulatory systems, including experiences of adversity and exposure to trauma during early life [154]), it is critical that researchers explicitly examine the role of puberty in this context.

It is also important that researchers in this area consider moving away from a nomothetic framework for the prediction of STBs and instead adopting idiographic or personcentered models. Puberty is a highly individualized process; adolescents differ markedly in their hormone levels, their neurobiological sensitivity to typical endocrine changes [14], their pubertal timing, their neurodevelopmental trajectories, and their psychological responses to maturation. Certainly, measuring these variables at the individual level is challenging and will have to take into account population norms on several dimensions (e.g., ethnicity, sociodemographic factors). Absent such data, standardization within age bands or residualized scores (e.g., regressing pubertal stage on age to obtain a measurement of pubertal timing) can be used to capture individual variability (for a treatment of these issues, see [159]). Another solution is to use "dense sampling" approaches that leverage repeated assessments (e.g., self-reported mood states, saliva samples, neurobiological measurements) from the same individual in order to capture intra-individual variation in these processes [13], which we argue is critical for understanding the contribution of ovarian hormones in risk for STBs in adolescent 


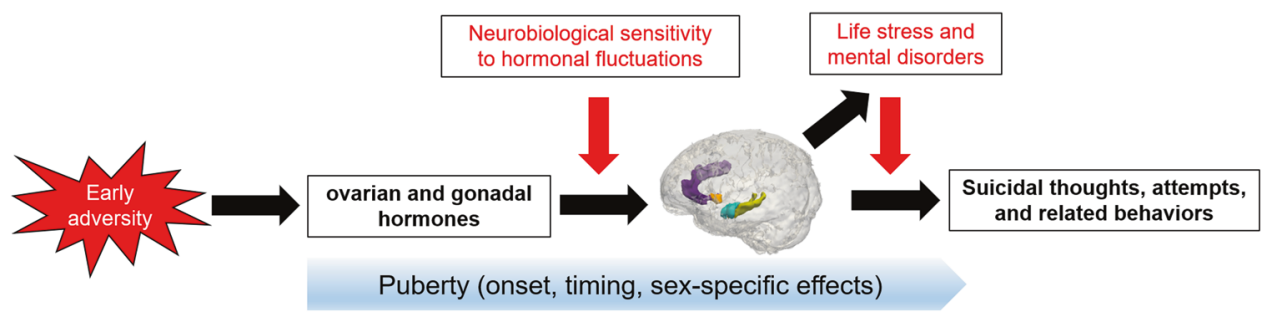

Fig. 2 Conceptual model linking aspects of the pubertal transition with risk for suicidal thoughts and behaviors. Experiences of early adversity affect the programming and development of endocrine and neural systems which undergo significant maturation during puberty. Puberty-related changes in ovarian, gonadal, and other related hormones shape the neural circuits underlying social cognition, emotion regulation, and impulse control (which include structures such as the amygdala, hippocampus, striatum, anterior cingulate cortex, and portions of prefrontal cortex). Alterations in these circuits may partially explain the ways in which changes in sex hormones are linked with the emergence of suicidal thoughts and behaviors during adolescence. Moderators of these processes, including a neurobiological sensitivity to ovarian hormones, experience of ongoing life stressors, and underlying mental disorders, are highlighted in red. females. Dense-sampling has the additional advantage of being able to identify proximal factors that lead to suicidal states and other related high-risk events, which are often transient and rarely captured in the laboratory or clinic [160].

Other important study design considerations include larger sample sizes of both sexes in order to detect sex differences more reliably. As we alluded to in the earlier sections of our review, there are other important confounds to consider that will affect the reliability and validity of estimating the effects of within-person changes in sex hormones on brain and behavior. These confounds include genetic factors, environmental influences, medical conditions, and cycle length (given that the range of menstrual cycles and periods of anovulation are longer in adolescents than in adults, particularly in the first few years post-menarche [161]). Finally, understanding the normative associations between changes in hormones with the structural and functional development of the brain is a critical next step that must be established before understanding how these alterations are altered in individuals at risk for STBs. Gaining a more comprehensive understanding of neurobiological trajectories and the mechanisms of neuroplasticity in adolescents as a consequence of puberty will also contribute to our knowledge of sex-specific psychiatric interventions and may help to address the heterogeneity of risk factors identified to date [5]. For instance, the granularity of data obtained from dense-sampling methods will facilitate the identification of individuals with hormonal sensitivity to the typical fluctuations occurring during puberty, as well as characterize withinperson pubertal processes associated with responses to social stressors and poorer impulse control during heightened emotional conflict. With this information, researchers and clinicians will be able to stratify individuals on the basis of neuroendocrine risk (e.g., those with hormone sensitivity) and also to identify points in time (e.g., dramatic increases in stress perception or depressive symptoms, unusual variability in DHEA) during which an individual might benefit from immediate intervention.

\section{Summary and conclusions}

Globally, suicide has surpassed all physical diseases as a cause of death in adolescents. Puberty drives psychobiological changes in adolescence that have not been examined explicitly in relation to suicide risk. In this review, we conceptualized suicidal thoughts and behaviors in adolescents as resulting from pathological responses to social stressors at a time when stress-regulatory systems are still maturing. We argued that alterations in brain circuitscomprised of connections among the amygdala, hippocampus, striatum, ACC, vmPFC, and $\mathrm{OFC}$ - that underlie social cognition, emotion regulation, and impulse control and are shaped by puberty-related changes in sex hormones. We propose that alterations in these circuits may partially explain the ways in which changes in sex hormones are linked with increased suicidal thoughts and behaviors during adolescence. However, we also highlighted critical moderators to be considered in this model, including a neurobiological sensitivity to fluctuations in ovarian hormones, exposure to early adversity, and underlying mental disorders (Fig. 2). To date, these specific hypotheses have not been tested. Although there is emerging research identifying shared and unique neural circuits that underlie suicidal thoughts and behaviors [68], it is paramount that that these associations be examined in prospective studies. It will also be important to use both experimental designs and large-scale longitudinal studies to elucidate the extent to which pubertal hormones affect the acute functioning of these circuits and drive the development of these circuits over the course of adolescence and young adulthood. Moreover, we expect that although pubertal hormones are not a primary driver of suicide risk, they may play an outsized role in individuals with a neurobiological sensitivity to hormonal fluctuations. Therefore, it is critical that we identify key moderators of the paths in our model, which we hypothesize includes neurobiological sensitivity to hormonal fluctuations, experiences of adversity and life 
stress that influence neurodevelopmental trajectories (which, in turn, may result in generating and experiencing additional stress), and underlying mental disorders. In addition to conducting longitudinal studies with larger sample sizes, we suggest that researchers also use densesampling methods to identify individuals according to these stratification parameters (e.g., hormonal sensitivity), as well as points in time at which individuals may be at risk and could benefit from more immediate intervention. In conclusion, we want to emphasize that increasing our understanding of pubertal science across endocrine, neural, and psychosocial domains will yield significant insights concerning how best to reduce the frequency of suicide-related deaths during the vulnerable period of adolescence.

Acknowledgements This work was supported by the National Institute of Mental Health (R37MH101495 to IHG, K01MH117442 to TCH), the Fonds de Recherche du Québec-Santé (FRQS/MSSS Resident Physician Health Research Career Training Program to AJG), Precision Health and Integrated Diagnostics Center at Stanford (PHIND to IHG and TCH), and the Ray and Dagmar Dolby Family Fund (to $\mathrm{TCH})$. The content is solely the responsibility of the authors and does not necessarily represent the official views of the National Institutes of Health. All authors report no biomedical conflicts of interest. The funding agencies played no role in the design and conduct of the study; collection, management, analysis, and interpretation of the data; and preparation, review, or approval of the manuscript.

\section{Compliance with ethical standards}

Conflict of interest The authors declare no competing interests.

Publisher's note Springer Nature remains neutral with regard to jurisdictional claims in published maps and institutional affiliations.

Open Access This article is licensed under a Creative Commons Attribution 4.0 International License, which permits use, sharing, adaptation, distribution and reproduction in any medium or format, as long as you give appropriate credit to the original author(s) and the source, provide a link to the Creative Commons license, and indicate if changes were made. The images or other third party material in this article are included in the article's Creative Commons license, unless indicated otherwise in a credit line to the material. If material is not included in the article's Creative Commons license and your intended use is not permitted by statutory regulation or exceeds the permitted use, you will need to obtain permission directly from the copyright holder. To view a copy of this license, visit http://creativecommons. org/licenses/by/4.0/.

\section{References}

1. Mokdad AH, Forouzanfar MH, Daoud F, Mokdad AA, El Bcheraoui C, Moradi-Lakeh M, et al. Global burden of diseases, injuries, and risk factors for young people's health during 1990-2013: a systematic analysis for the Global Burden of Disease Study 2013. Lancet. 2016;387:2383-401.

2. Murphy SL, Mathews TJ, Martin JA, Minkovitz CS, Strobino DM Annual Summary of Vital Statistics: 2013-2014. Pediatrics
[Internet]. 2017 [cited 2020 Apr 10];139. Available from: https:// pediatrics.aappublications.org/content/139/6/e20163239

3. Curtin SC, Heron M. Death rates due to suicide and homicide among persons aged 10-24: United States, 2000-2017. NCHS Data Brief. 2019;352:1-8.

4. Carter G, Milner A, McGill K, Pirkis J, Kapur N, Spittal MJ. Predicting suicidal behaviours using clinical instruments: Systematic review and meta-analysis of positive predictive values for risk scales. Br J Psychiatry. 2017;210:387-95.

5. Franklin JC, Ribeiro JD, Fox KR, Bentley KH, Kleiman EM, Huang $X$, et al. Risk factors for suicidal thoughts and behaviors: a meta-analysis of 50 years of research. Psychol Bull. 2017; 143:187-232.

6. Cha CB, Franz PJ, Guzmán EM, Glenn CR, Kleiman EM, Nock MK. Annual research review: suicide among youth - epidemiology, (potential) etiology, and treatment. J Child Psychol Psychiatry. 2018;59:460-82.

7. Glenn CR, Kleiman EM, Kellerman J, Pollak O, Cha CB, Esposito EC, et al. Annual research review: a meta-analytic review of worldwide suicide rates in adolescents. J Child Psychol Psychiatry. 2020;61:294-308.

8. Nelson EE, Leibenluft E, McClure EB, Pine DS. The social reorientation of adolescence: a neuroscience perspective on the process and its relation to psychopathology. Psychol Med. 2005;35:163-74.

9. Paus T, Keshavan M, Giedd JN. Why do many psychiatric disorders emerge during adolescence? Nat Rev Neurosci. 2008; 9:947-57.

10. Rudolph KD Puberty as a Developmental Context of Risk for Psychopathology. In: Lewis M, Rudolph KD, editors. Handbook of Developmental Psychopathology. Boston, MA: Springer US; 2014. p. 331-54.

11. O'Connor RC, Nock MK. The psychology of suicidal behaviour. Lancet Psychiatry. 2014;1:73-85.

12. Lutz P-E, Mechawar N, Turecki G. Neuropathology of suicide: recent findings and future directions. Mol Psychiatry. 2017;22:1395-412.

13. Miller AB, Prinstein MJ. Adolescent suicide as a failure of acute stress-response systems. Annu Rev Clin Psychol. 2019;07:425-50.

14. Owens SA, Eisenlohr-Moul T. Suicide risk and the menstrual cycle: a review of candidate rdoc mechanisms. Curr Psychiatry Rep. 2018;20:106.

15. King CA, Merchant CR. Social and interpersonal factors relating to adolescent suicidality: a review of the literature. Arch Suicide Res. 2008;12:181-96.

16. Liu RT, Miller I. Life events and suicidal ideation and behavior: a systematic review. Clin Psychol Rev. 2014;34:181-92.

17. Stewart JG, Shields GS, Esposito EC, Cosby EA, Allen NB, Slavich GM, et al. Life stress and suicide in adolescents. J Abnorm Child Psychol. 2019;47:1707-22.

18. Platt B, Cohen Kadosh K, Lau JYF. The role of peer rejection in adolescent depression. Depress Anxiety. 2013;30:809-21.

19. Prinstein MJ, Giletta M Peer relations and developmental psychopathology. In: Developmental psychopathology: theory and method, Vol 1, 3rd ed. Hoboken, NJ, US: John Wiley \& Sons Inc; 2016. p. 527-79.

20. Whiteside SP, Lynam DR, Miller JD, Reynolds SK. Validation of the UPPS impulsive behaviour scale: a four-factor model of impulsivity. Eur J Personal. 2005;19:559-74.

21. Eisenlohr-Moul TA, Miller AB, Giletta M, Hastings PD, Rudolph KD, Nock MK, et al. HPA axis response and psychosocial stress as interactive predictors of suicidal ideation and behavior in adolescent females: a multilevel diathesis-stress framework. Neuropsychopharmacology 2018;43:2564-71. 
22. van Geel M, Vedder P, Tanilon J. Relationship between peer victimization, cyberbullying, and suicide in children and adolescents: a meta-analysis. JAMA Pediatr. 2014;168:435-42.

23. Auerbach RP, Stewart JG, Johnson SL. Impulsivity and suicidality in adolescent inpatients. J Abnorm Child Psychol. 2017;45:91-103.

24. Mahfouz A, Lelieveldt BPF, Grefhorst A, van Weert LTCM, Mol IM, Sips HCM. et al. Genome-wide coexpression of steroid receptors in the mouse brain: identifying signaling pathways and functionally coordinated regions. Proc Natl Acad Sci USA. 2016;113:2738-43.

25. McEwen BS, Milner TA. Understanding the broad influence of sex hormones and sex differences in the brain. J Neurosci Res. 2017;95:24-39.

26. Kaczkurkin AN, Raznahan A, Satterthwaite TD. Sex differences in the developing brain: insights from multimodal neuroimaging. Neuropsychopharmacology 2019;44:71-85.

27. Scheinost D, Finn ES, Tokoglu F, Shen X, Papademetris X, Hampson M, et al. Sex differences in normal age trajectories of functional brain networks. Hum Brain Mapp. 2015;36:1524-35.

28. Schmaal L, van Harmelen A-L, Chatzi V, Lippard ETC, Toenders YJ, Averill LA, et al. Imaging suicidal thoughts and behaviors: a comprehensive review of 2 decades of neuroimaging studies. Mol Psychiatry. 2020;25:408-27.

29. Ho TC, Colich NL, Sisk LM, Oskirko K, Jo B, Gotlib IH. Sex differences in the effects of gonadal hormones on white matter microstructure development in adolescence. Dev Cogn Neurosci. 2020;42:100773.

30. Vijayakumar N, Op de Macks Z, Shirtcliff EA, Pfeifer JH. Puberty and the human brain: Insights into adolescent development. Neurosci Biobehav Rev. 2018;92:417-36.

31. Reiter EO, Fuldauer VG, Root AW. Secretion of the adrenal androgen, dehydroepiandrosterone sulfate, during normal infancy, childhood, and adolescence, in sick infants, and in children with endocrinologic abnormalities. J Pediatr. 1977;90:766-70.

32. Søeborg T, Frederiksen H, Mouritsen A, Johannsen TH, Main KM, Jørgensen N. et al. Sex, age, pubertal development and use of oral contraceptives in relation to serum concentrations of DHEA, DHEAS, 17 $\alpha$-hydroxyprogesterone, $\Delta 4$-androstenedione, testosterone and their ratios in children, adolescents and young adults. Clin Chim Acta. 2014;437:6-13.

33. Dorn LD, Dahl RE, Woodward HR, Biro F. Defining the boundaries of early adolescence: A user's guide to assessing pubertal status and pubertal timing in research with adolescents. Appl Dev Sci. 2006;10:30-56.

34. Schulz KM, Sisk CL. The organizing actions of adolescent gonadal steroid hormones on brain and behavioral development. Neurosci Biobehav Rev. 2016;70:148-58.

35. Piekarski DJ, Johnson CM, Boivin JR, Thomas AW, Lin WC, Delevich $\mathrm{K}$, et al. Does puberty mark a transition in sensitive periods for plasticity in the associative neocortex? Brain Res. 2017;1654:123-44.

36. Juraska JM, Willing J. Pubertal onset as a critical transition for neural development and cognition. Brain Res. 2017;1654:87-94.

37. Saunders KEA, Hawton K. Suicidal behaviour and the menstrual cycle. Psychol Med. 2006;36:901-12.

38. Osborn E, Brooks J, O'Brien PMS, Wittkowski A Suicidality in women with premenstrual dysphoric disorder: a systematic literature review. Arch Womens Ment Health [Internet]. 2020 Sep 16 [cited 2021 Mar 13]; Available from: https://doi.org/10.1007/ s00737-020-01054-8

39. Shams-Alizadeh N, Maroufi A, Rashidi M, Roshani D, Farhadifar F, Khazaie H. Premenstrual dysphoric disorder and suicide attempts as a correlation among women in reproductive age. Asian J Psychiatry. 2018;31:63-6.
40. Wei S-M, Schiller CE, Schmidt PJ, Rubinow DR. The role of ovarian steroids in affective disorders. Curr Opin Behav Sci.2018;23:103-12.

41. Schmidt PJ, Martinez PE, Nieman LK, Koziol DE, Thompson KD, Schenkel L, et al. Exposure to a change in ovarian steroid levels but not continuous stable levels triggers PMDD symptoms following ovarian suppression. Am J Psychiatry. 2017;174:980-9.

42. Dogra TD, Leenaars AA, Raintji R, Lalwani S, Girdhar S, Wenckstern S, et al. Menstruation and suicide: an exploratory study. Psychol Rep. 2007;101:430-4.

43. Zengin Y, Çalık I, Büyükcam F, Şen J, Akpınar Ş, Erdem A, et al. The relationship between suicide attempts and menstrual cycles in the emergency department and the sociodemographic and clinical characteristics of these patients. Eurasia J Emerg Med. 2015;14:118-22.

44. Afzali S, Taheri SK, Jamilian M, Eslambolchi P. The relationship between menstrual cycle phases and suicide attempts in suicidal women admitted to the poisoning ward of Farshchian Hospital, Hamedan, Iran. Iran J Toxicol. 2012;5:531-4.

45. Baca-Garcia E, Diaz-Sastre C, Ceverino A, Perez-Rodriguez MM, Navarro-Jimenez R, Lopez-Castroman J, et al. Suicide attempts among women during low estradiol/low progesterone states. J Psychiatr Res. 2010;44:209-14.

46. Kim B, Kang E-S, Fava M, Mischoulon D, Soskin D, Yu B-H, et al. Follicle-stimulating hormone (FSH), current suicidal ideation and attempt in female patients with major depressive disorder. Psychiatry Res. 2013;210:951-6.

47. Sun BZ, Kangarloo T, Adams JM, Sluss PM, Welt CK, Chandler DW, et al. Healthy post-menarchal adolescent girls demonstrate multi-level reproductive axis immaturity. J Clin Endocrinol Metab. 2018;104:613-23.

48. Chatterton RT, Mateo ET, Hou N, Rademaker AW, Acharya S, Jordan VC, et al. Characteristics of salivary profiles of oestradiol and progesterone in premenopausal women. $\mathrm{J}$ Endocrinol. 2005;186:77-84.

49. Gann PH, Giovanazzi S, Van Horn L, Branning A, Chatterton RT.Saliva as a medium for investigating intra- and interindividual differences in sex hormone levels in premenopausal women.Cancer Epidemiol Biomark Prev. 2001;10:59-64.

50. Landgren B-M, Undén A-L, Diczfalusy E. Hormonal profile of the cycle in 68 normally menstruating women. Eur J Endocrinol. 1980;94:89-98.

51. Shirtcliff EA, Dahl RE, Pollak SD. Pubertal development: correspondence between hormonal and physical development. Child Dev. 2009;80:327-37.

52. Hambridge HL, Mumford SL, Mattison DR, Ye A, Pollack AZ, Bloom MS, et al. The influence of sporadic anovulation on hormone levels in ovulatory cycles. Hum Reprod Oxf Engl. 2013;28:1687-94.

53. Ellison PT, Panter-Brick C, Lipson SF, O'Rourke MT. The ecological context of human ovarian function. Hum Reprod Oxf Engl. 1993;8:2248-58.

54. Lobo RA, Granger L, Goebelsmann U, Mishell DR. Elevations in unbound serum estradiol as a possible mechanism for inappropriate gonadotropin secretion in women with PCO. J Clin Endocrinol Metab. 1981;52:156-8.

55. Cover KK, Maeng LY, Lebrón-Milad K, Milad MR. Mechanisms of estradiol in fear circuitry: implications for sex differences in psychopathology. Transl Psychiatry. 2014;4:e422.

56. Maner JK, Miller SL. Hormones and social monitoring: menstrual cycle shifts in progesterone underlie women's sensitivity to social information. Evol Hum Behav. 2014;35:9-16.

57. Sheppard PAS, Choleris E, Galea LAM. Structural plasticity of the hippocampus in response to estrogens in female rodents. Mol Brain. 2019;12:22. 
58. Wang ACJ, Hara Y, Janssen WGM, Rapp PR, Morrison JH. Synaptic estrogen receptor- $\alpha$ levels in prefrontal cortex in female rhesus monkeys and their correlation with cognitive performance. $\mathbf{J}$ Neurosci. 2010;30:12770-6.

59. Engman J, Sundström Poromaa I, Moby L, Wikström J, Fredrikson M, Gingnell M. Hormonal cycle and contraceptive effects on amygdala and salience resting-state networks in women with previous affective side effects on the pill. Neuropsychopharmacology. 2018;43:555-63.

60. Engman J, Linnman C, Van Dijk KRA, Milad MR. Amygdala subnuclei resting-state functional connectivity sex and estrogen differences. Psychoneuroendocrinology. 2016;63:34-42.

61. Miedl SF, Wegerer M, Kerschbaum H, Blechert J, Wilhelm FH. Neural activity during traumatic film viewing is linked to endogenous estradiol and hormonal contraception. Psychoneuroendocrinology. 2018;87:20-6.

62. Protopopescu X, Butler T, Pan H, Root J, Altemus M, Polanecsky $M$, et al. Hippocampal structural changes across the menstrual cycle. Hippocampus. 2008;18:985-8.

63. Lisofsky N, Mårtensson J, Eckert A, Lindenberger U, Gallinat J, Kühn S. Hippocampal volume and functional connectivity changes during the female menstrual cycle. NeuroImage. 2015;118:154-62.

64. Pletzer B, Harris T-A, Scheuringer A, Hidalgo-Lopez E. The cycling brain: menstrual cycle related fluctuations in hippocampal and fronto-striatal activation and connectivity during cognitive tasks. Neuropsychopharmacology. 2019;44:1867-75.

65. Albert K, Pruessner J, Newhouse P. Estradiol levels modulate brain activity and negative responses to psychosocial stress across the menstrual cycle. Psychoneuroendocrinology. 2015; 59:14-24.

66. Arélin K, Mueller K, Barth C, Rekkas PV, Kratzsch J, Burmann I, et al. Progesterone mediates brain functional connectivity changes during the menstrual cycle - a pilot resting state MRI study. Front Neurosci [Internet]. 2015 Feb 23 [cited 2020 Apr 11];9. Available from: https://www.ncbi.nlm.nih.gov/pmc/articles/PMC4337344/

67. Pritschet L, Santander T, Layher E, Taylor CM, Yu S, Miller $\mathrm{MB}$, et al. Functional reorganization of brain networks across the human menstrual cycle. bioRxiv. 2019 Dec 6;866913.

68. Auerbach RP, Pagliaccio D, Allison GO, Alqueza KL, Alonso MF. Neural correlates associated with suicide and nonsuicidal self-injury in youth. Biol Psychiatry. 2020;89:119-33.

69. Rybaczyk LA, Bashaw MJ, Pathak DR, Moody SM, Gilders RM, Holzschu DL. An overlooked connection: serotonergic mediation of estrogen-related physiology and pathology. BMC Women's Health. 2005;5:12

70. Sullivan GM, Oquendo MA, Milak M, Miller JM, Burke A, Ogden RT, et al. Positron emission tomography quantification of serotonin(1 A) receptor binding in suicide attempters with major depressive disorder. JAMA Psychiatry. 2015;72:169-78.

71. Oquendo MA, Galfalvy H, Sullivan GM, Miller JM, Milak MM, Sublette ME, et al. Positron emission tomographic imaging of the serotonergic system and prediction of risk and lethality of future suicidal behavior. JAMA Psychiatry. 2016;73:1048-55.

72. Mann JJ The serotonergic system in mood disorders and suicidal behaviour. Philos Trans R Soc B Biol Sci [Internet]. 2013 [cited 2020 Apr 11];368. Available from: https://www.ncbi.nlm.nih. gov/pmc/articles/PMC3638390/

73. Steinberg LJ, Rubin-Falcone H, Galfalvy HC, Kaufman J, Miller $\mathrm{JM}$, Sublette ME, et al. Cortisol stress response and in vivo PET imaging of human brain serotonin $1 \mathrm{~A}$ receptor binding. Int $\mathrm{J}$ Neuropsychopharmacol. 2019;22:329-38.

74. Underwood MD, Kassir SA, Bakalian MJ, Galfalvy H, Dwork AJ, Mann JJ, et al. Serotonin receptors and suicide, major depression, alcohol use disorder and reported early life adversity. Transl Psychiatry. 2018;8:1-15.
75. Mellon SH, Griffin LD. Neurosteroids: biochemistry and clinical significance. Trends Endocrinol Metab TEM. 2002;13:35-43.

76. Giordano R, Picu A, Bonelli L, Balbo M, Berardelli R, Marinazzo E, et al. Hypothalamus-pituitary-adrenal axis evaluation in patients with hypothalamo-pituitary disorders: comparison of different provocative tests. Clin Endocrinol (Oxf). 2008;68:935-41.

77. Gunn JF, Lester D, McSwain S. Testing the warning signs of suicidal behavior among suicide ideators using the 2009 National survey on drug abuse and health. Int J Emerg Ment Health. 2011;13:147-54.

78. Skilbeck KJ, Johnston GAR, Hinton T. Stress and GABAA receptors. J Neurochem. 2010;112:1115-30.

79. Hu W, Zhang M, Czéh B, Flügge G, Zhang W. Stress impairs GABAergic network function in the hippocampus by activating nongenomic glucocorticoid receptors and affecting the integrity of the parvalbumin-expressing neuronal network. Neuropsychopharmacology 2010;35:1693-707.

80. Zhao J, Verwer RWH, Gao S-F, Qi X-R, Lucassen PJ, Kessels $\mathrm{HW}$, et al. Prefrontal alterations in GABAergic and glutamatergic gene expression in relation to depression and suicide. $\mathrm{J}$ Psychiatr Res. 2018;102:261-74.

81. Archer J. Testosterone and human aggression: an evaluation of the challenge hypothesis. Neurosci Biobehav Rev. 2006;30: $319-45$.

82. van Anders SM. Beyond masculinity: testosterone, gender/sex, and human social behavior in a comparative context. Front Neuroendocrinol. 2013;34:198-210.

83. Halpern CT, Udry JR, Campbell B, Suchindran C. Relationships between aggression and pubertal increases in testosterone: a panel analysis of adolescent males. Soc Biol. 1993;40:8-24.

84. Rice TR, Sher L Adolescent suicide and testosterone: Postnatal testosterone may be an important mediator of the association between prematurity and male neurodevelopmental disorders: A Hypothesis. Int J Adolesc Med Health [Internet]. 2015 Nov 4 [cited 2020 Apr 11];29. Available from: https://www.degruyter. com/view/journals/ijamh/29/4/article-20150058.xml

85. Perez-Rodriguez MM, Lopez-Castroman J, Martinez-Vigo M, DiazSastre C, Ceverino A, Núñez-Beltrán A, et al. Lack of association between testosterone and suicide attempts. Neuropsychobiology. 2011;63:125-30.

86. McGirr A, Turecki G. The relationship of impulsive aggressiveness to suicidality and other depression-linked behaviors. Curr Psychiatry Rep. 2007;9:460-6.

87. Eisenegger C, Haushofer J, Fehr E. The role of testosterone in social interaction. Trends Cogn Sci. 2011;15:263-71.

88. Duke SA, Balzer BWR, Steinbeck KS. Testosterone and its effects on human male adolescent mood and behavior: a systematic review. J Adolesc Health. 2014;55:315-22.

89. van Bokhoven I, van Goozen SHM, van Engeland H, Schaal B, Arseneault L, Séguin JR, et al. Salivary testosterone and aggression, delinquency, and social dominance in a populationbased longitudinal study of adolescent males. Horm Behav. 2006;50:118-25.

90. Schaal B, Tremblay RE, Soussignan R, Susman EJ. Male testosterone linked to high social dominance but low physical aggression in early adolescence. J Am Acad Child Adolesc Psychiatry. 1996;35:1322-30.

91. Milner A, Page A, Morrell S, Hobbs C, Carter G, Dudley M, et al. The effects of involuntary job loss on suicide and suicide attempts among young adults: evidence from a matched casecontrol study. Aust N Z J Psychiatry. 2014;48:333-40.

92. Stefansson J, Chatzittofis A, Nordström P, Arver S, Åsberg M, Jokinen J. CSF and plasma testosterone in attempted suicide. Psychoneuroendocrinology 2016;74:1-6. 
93. Gustavsson G, Träskman-Bendz L, Higley JD, Westrin Å. CSF testosterone in 43 male suicide attempters. Eur Neuropsychopharmacol. 2003;13:105-9.

94. Zhang J, Jia C-X, Wang L-L. Testosterone differs between suicide attempters and community controls in men and women of China. Physiol Behav. 2015;141:40-5.

95. Roland BC, Morris JL, Zelhart PF. Proposed relation of testosterone levels to male suicides and sudden deaths. Psychol Rep. 1986;59:100-2.

96. Sher L, Grunebaum MF, Sullivan GM, Burke AK, Cooper TB, Mann JJ, et al. Testosterone levels in suicide attempters with bipolar disorder. J Psychiatr Res. 2012;46:1267-71.

97. Sher L, Grunebaum MF, Sullivan GM, Burke AK, Cooper TB, Mann JJ, et al. Association of testosterone levels and future suicide attempts in females with bipolar disorder. J Affect Disord. 2014;166:98-102.

98. Tripodianakis J, Markianos M, Rouvali O, Istikoglou C. Gonadal axis hormones in psychiatric male patients after a suicide attempt. Eur Arch Psychiatry Clin Neurosci. 2007;257:135-9.

99. Markianos M, Tripodianakis J, Istikoglou C, Rouvali O, Christopoulos M, Papageorgopoulos $\mathrm{P}$, et al. Suicide attempt by jumping: a study of gonadal axis hormones in male suicide attempters versus men who fell by accident. Psychiatry Res. 2009;170:82-5.

100. Shay DA, Vieira-Potter VJ, Rosenfeld CS Sexually Dimorphic Effects of Aromatase on Neurobehavioral Responses. Front Mol Neurosci [Internet]. 2018 [cited 2020 Apr 17];11. Available from: https://www.frontiersin.org/articles/10.3389/fnmol.2018. 00374/full

101. Fitzgerald ML, Kassir SA, Underwood MD, Bakalian MJ, Mann JJ, Arango V. Dysregulation of Striatal Dopamine Receptor Binding in Suicide. Neuropsychopharmacology. 2017;42:974-82.

102. Pitchot W, Hansenne M, Ansseau M. Role of dopamine in nondepressed patients with a history of suicide attempts. Eur Psychiatry. 2001;16:424-7.

103. Roy A, Karoum F, Pollack S. Marked reduction in indexes of dopamine metabolism among patients with depression who attempt suicide. Arch Gen Psychiatry. 1992;49:447-50.

104. Tobiansky DJ, Wallin-Miller KG, Floresco SB, Wood RI, Soma KK Androgen Regulation of the Mesocorticolimbic System and Executive Function. Front Endocrinol [Internet]. 2018 [cited 2020 Apr 14];9. Available from: https://www.frontiersin.org/a rticles/10.3389/fendo.2018.00279/full

105. Sinclair D, Purves-Tyson TD, Allen KM, Weickert CS. Impacts of stress and sex hormones on dopamine neurotransmission in the adolescent brain. Psychopharmacol. 2014;231:1581-99.

106. Wahlstrom D, Collins P, White T, Luciana M. Developmental changes in dopamine neurotransmission in adolescence: behavioral implications and issues in assessment. Brain Cogn. 2010;72:146-59.

107. Pitchot W, Hansenne M, Moreno AG, Ansseau M. Dopamine and history of suicide attempts. Clin Neuropharmacol. 1992;15:296B.

108. Happe S, Tings T, Koch W, Welsch J, Helmschmied K, Baier $\mathrm{PC}$, et al. Growth hormone response in low-dose apomorphine test correlates with nigrostriatal dopamine transporter binding in patients with Parkinson's disease. J Neural Transm Vienna Austria 1996. 2007;114:589-94.

109. Oquendo MA, Sullivan GM, Sudol K, Baca-Garcia E, Stanley BH, Sublette ME, et al. Toward a Biosignature for Suicide. Am J Psychiatry. 2014;171:1259-77.

110. Barendse MEA, Simmons JG, Byrne ML, Seal ML, Patton G, Mundy L, et al. Brain structural connectivity during adrenarche: associations between hormone levels and white matter microstructure. Psychoneuroendocrinology. 2018;88:70-7.

111. Menzies L, Goddings A-L, Whitaker KJ, Blakemore S-J, Viner RM. The effects of puberty on white matter development in boys. Dev Cogn Neurosci. 2015;11:116-28.
112. Peper JS, Reus MA, de, Heuvel MP, van den, Schutter DJLG. Short fused? associations between white matter connections, sex steroids, and aggression across adolescence. Hum Brain Mapp. 2015;36:1043-52.

113. Bos PA, van Honk J, Ramsey NF, Stein DJ, Hermans EJ. Testosterone administration in women increases amygdala responses to fearful and happy faces. Psychoneuroendocrinology. 2013;38:808-17.

114. Spielberg JM, Olino TM, Forbes EE, Dahl RE. Exciting fear in adolescence: does pubertal development alter threat processing? Dev Cogn Neurosci. 2014;8:86-95.

115. Cservenka A, Stroup ML, Etkin A, Nagel BJ. The effects of age, sex, and hormones on emotional conflict-related brain response during adolescence. Brain Cogn. 2015;99:135-50.

116. Op de Macks ZA, Moor BG, Overgaauw S, Güroğlu B, Dahl RE, Crone EA. Testosterone levels correspond with increased ventral striatum activation in response to monetary rewards in adolescents. Dev Cogn Neurosci. 2011;1:506-16.

117. Laube C, van den Bos W, Fandakova Y. The relationship between pubertal hormones and brain plasticity: Implications for cognitive training in adolescence. Dev Cogn Neurosci. 2020;42:100753.

118. Braams BR, van Duijvenvoorde ACK, Peper JS, Crone EA. Longitudinal changes in adolescent risk-taking: a comprehensive study of neural responses to rewards, pubertal development, and risk-taking behavior. J Neurosci J Soc Neurosci. 2015;35:7226-38.

119. White SF, Lee Y, Schlund MW, Shirtcliff EA, Ladouceur CD. Testosterone reactivity is associated with reduced neural response to reward in early adolescence. Behav Brain Res. 2020; 387:112593.

120. Coates JM, Herbert J. Endogenous steroids and financial risk taking on a London trading floor. Proc Natl Acad Sci. 2008; 105:6167-72.

121. Stanton SJ, Liening SH, Schultheiss OC. Testosterone is positively associated with risk taking in the Iowa Gambling Task. Horm Behav. 2011;59:252-6.

122. Richard-Devantoy S, Berlim MT, Jollant F. A meta-analysis of neuropsychological markers of vulnerability to suicidal behavior in mood disorders. Psychol Med. 2014;44:1663-73.

123. Gifuni AJ, Perret LC, Lacourse E, Geoffroy M-C, Mbekou V, Jollant $\mathrm{F}$, et al. Decision-making and cognitive control in adolescent suicidal behaviors: a qualitative systematic review of the literature. Eur Child Adolesc Psychiatry [Internet]. 2020 May 9 [cited 2021 Mar 8]; Available from: https://doi.org/10.1007/ s00787-020-01550-3

124. Chatzittofis A, Nordström P, Hellström C, Arver S, Åsberg M, Jokinen J. CSF 5-HIAA, cortisol and DHEAS levels in suicide attempters. Eur Neuropsychopharmacol. 2013;23:1280-7.

125. Butterfield MI, Stechuchak KM, Connor KM, Davidson JRT, Wang C, MacKuen CL, et al. Neuroactive steroids and suicidality in posttraumatic stress disorder. Am J Psychiatry. 2005;162:380-2.

126. Sher L, Flory J, Bierer L, Makotkine I, Yehuda R. Dehydroepiandrosterone and dehydroepiandrosterone sulfate levels in combat veterans with or without a history of suicide attempt. Acta Psychiatr Scand. 2018;138:55-61.

127. Sequeira A, Shen K, Gottlieb A, Limon A.Human brain transcriptome analysis finds region- and subject-specific expression signatures of GABA A R subunits. Commun Biol. 2019;2:1-14.

128. Pineles SL, Nillni YI, Pinna G, Irvine J, Webb A, Arditte Hall KA, et al. PTSD in women is associated with a block in conversion of progesterone to the GABAergic neurosteroids allopregnanolone and pregnanolone measured in plasma. Psychoneuroendocrinology. 2018;93:133-41.

129. Locci A, Pinna G. Neurosteroid biosynthesis down-regulation and changes in GABAA receptor subunit composition: a biomarker axis in stress-induced cognitive and emotional impairment. Br J Pharm. 2017;174:3226-41. 
130. Ellis R, Fernandes A, Simmons JG, Mundy L, Patton G, Allen $\mathrm{NB}$, et al. Relationships between adrenarcheal hormones, hippocampal volumes and depressive symptoms in children. Psychoneuroendocrinology. 2019;104:55-63.

131. Barendse MEA, Simmons JG, Patton G, Mundy L, Byrne ML, Seal ML, et al. Adrenarcheal timing longitudinally predicts anxiety symptoms via amygdala connectivity during emotion processing. J Am Acad Child Adolesc Psychiatry [Internet]. 2019 May 2 [cited 2020 Apr 12]. Available from: https://www. jaacap.org/article/S0890-8567(19)30286-2/abstract

132. Whittle S, Simmons JG, Byrne ML, Strikwerda-Brown C, Kerestes R, Seal ML, et al. Associations between early adrenarche, affective brain function and mental health in children. Soc Cogn Affect Neurosci. 2015;10:1282-90.

133. Sripada RK, Marx CE, King AP, Rajaram N, Garfinkel SN, Abelson JL, et al. DHEA enhances emotion regulation neurocircuits and modulates memory for emotional stimuli. Neuropsychopharmacology. 2013;38:1798-807.

134. McLoughlin AB, Gould MS, Malone KM. Global trends in teenage suicide: 2003-2014. QJM Mon J Assoc Phys. 2015; 108:765-80.

135. WHO I Preventing suicide: a global imperative [Internet]. WHO. World Health Organization; [cited 2020 Mar 26]. Available from: http://www.who.int/mental_health/suicide-prevention/world_report_ 2014/en/

136. Ruch DA, Sheftall AH, Schlagbaum P, Rausch J, Campo JV, Bridge JA.Trends in suicide among youth aged 10 to 19 years in the United States, 1975 to 2016. JAMA Netw Open.2019;2: e193886.

137. Lewinsohn PM, Rohde P, Seeley JR, Baldwin CL. Gender differences in suicide attempts from adolescence to young adulthood. J Am Acad Child Adolesc Psychiatry. 2001; 40:427-34.

138. Boeninger DK, Masyn KE, Feldman BJ, Conger RD. Sex differences in developmental trends of suicide ideation, plans, and attempts among European American adolescents. Suicide Life Threat Behav. 2010;40:451-64.

139. Miranda-Mendizabal A, Castellví P, Parés-Badell O, Alayo I, Almenara J, Alonso I, et al. Gender differences in suicidal behavior in adolescents and young adults: systematic review and meta-analysis of longitudinal studies. Int J Public Health. 2019; 64:265-83.

140. Brent DA, Baugher M, Bridge J, Chen T, Chiappetta L. Age- and sex-related risk factors for adolescent suicide. J Am Acad Child Adolesc Psychiatry. 1999;38:1497-505.

141. Dorn LD, Biro FM. Puberty and its measurement: a decade in review. J Res Adolesc. 2011;21:180-95.

142. Graber JA. Pubertal timing and the development of psychopathology in adolescence and beyond. Horm Behav. 2013;64:262-9.

143. Kaltiala-Heino R, Marttunen M, Rantanen P, Rimpelä M. Early puberty is associated with mental health problems in middle adolescence. Soc Sci Med. 2003;57:1055-64.

144. Lee D, Ahn I-Y, Park C-S, Kim B-J, Lee C-S, Cha B, et al. Early menarche as a risk factor for suicidal ideation in girls: The Korea youth risk behavior web-based survey. Psychiatry Res. 2020;285:112706.
145. Nacinovich R, Buzi F, Oggiano S, Rossi S, Spada S, Broggi F, et al. Body experiences and psychopathology in idiopathic central precocious and early puberty. Minerva Pediatr. 2016;68:11-8.

146. Stice E, Presnell K, Bearman SK. Relation of early menarche to depression, eating disorders, substance abuse, and comorbid psychopathology among adolescent girls. Dev Psychol. 2001; 37:608-19.

147. Roberts E, Fraser A, Gunnell D, Joinson C, Mars B. Timing of menarche and self-harm in adolescence and adulthood: a population-based cohort study. Psychol Med. 2020;50:2010-8.

148. Belsky J, Steinberg LD, Houts RM, Friedman SL, DeHart G, Cauffman E, et al. Family rearing antecedents of pubertal timing. Child Dev. 2007;78:1302-21.

149. Turecki G, Ernst C, Jollant F, Labonté B, Mechawar N. The neurodevelopmental origins of suicidal behavior. Trends Neurosci. 2012;35:14-23.

150. Wichstrøm L, Hegna K. Sexual orientation and suicide attempt: A longitudinal study of the general Norwegian adolescent population. J Abnorm Psychol. 2003;112:144-51.

151. Klonsky ED, Saffer BY, Bryan CJ. Ideation-to-action theories of suicide: a conceptual and empirical update. Curr Opin Psychol. 2018;22:38-43.

152. Beauchaine TP, Crowell SE, Hsiao RC. Post-dexamethasone cortisol, self-inflicted injury, and suicidal ideation among depressed adolescent girls. J Abnorm Child Psychol. 2015;43:619-32.

153. Shalev A, Porta G, Biernesser C, Zelazny J, Walker-Payne M, Melhem N, et al. Cortisol response to stress as a predictor for suicidal ideation in youth. J Affect Disord. 2019;257:10-6.

154. King LS, Graber MG, Colich NL, Gotlib IH. Associations of waking cortisol with DHEA and testosterone across the pubertal transition: effects of threat-related early life stress. Psychoneuroendocrinology. 2020;115:104651.

155. Maninger N, Wolkowitz OM, Reus VI, Epel ES, Mellon SH. Neurobiological and neuropsychiatric effects of dehydroepiandrosterone (DHEA) and DHEA sulfate (DHEAS). Front Neuroendocrinol. 2009;30:65-91.

156. Oyola MG, Handa RJ. Hypothalamic-pituitary-adrenal and hypothalamic-pituitary-gonadal axes: sex differences in regulation of stress responsivity. Stress Amst Neth 2017;20:476-94.

157. Toufexis D, Rivarola MA, Lara H, Viau V. Stress and the reproductive axis. J Neuroendocrinol. 2014;26:573-86.

158. Mastorakos G, Pavlatou MG, Mizamtsidi M. The hypothalamicpituitary-adrenal and the hypothalamic- pituitary-gonadal axes interplay. Pediatr Endocrinol Rev. 2006;3:172-81.

159. Mendle J, Beltz AM, Carter R, Dorn LD. Understanding puberty and its measurement: ideas for research in a new generation. $J$ Res Adolesc. 2019;29:82-95.

160. Kleiman EM, Turner BJ, Fedor S, Beale EE, Picard RW, Huffman JC, et al. Digital phenotyping of suicidal thoughts. Depress Anxiety. 2018;35:601-8.

161. Rosenfield RL. Adolescent anovulation: maturational mechanisms and implications. J Clin Endocrinol Metab. 2013;98:3572-83.

162. Østby Y, Tamnes CK, Fjell AM, Westlye LT, Due-Tønnessen P, Walhovd KB. Heterogeneity in subcortical brain development: a structural magnetic resonance imaging study of brain maturation from 8 to 30 years. J Neurosci. 2009;29:11772-82. 